\title{
Positive urine cultures: A major cause of inappropriate antimicrobial use in hospitals?
}

\author{
Samuel A Silver MD ${ }^{1,3}$, Laura Baillie BSC ART ${ }^{1}$, Andrew E Simor MD FRCPC $1,2,3$
}

SA Silver, L Baillie, AE Simor. Positive urine cultures: A major cause of inappropriate antimicrobial use in hospitals. Can J Infect Dis Med Microbiol 2009;20(4):107-111.

INTRODUCTION: Urine specimens are among the most common samples submitted for culture to microbiology laboratories. The objectives of the present study were to describe the indications for obtaining urine cultures in a cohort of hospitalized patients, and to determine the appropriateness of antimicrobial therapy in response to urine culture results.

METHODS: The study was performed at a teaching hospital with an adjoining long-term care facility from June 1 to July 31, 2006. The medical records of nonpregnant adult patients with and without bacteriuria were reviewed. A symptomatic urinary tract infection was defined as the presence of bacteriuria in a patient with fever or urinary symptoms; asymptomatic bacteriuria was defined as bacteriuria without urinary symptoms and no infection evident at another site.

RESULTS: Medical records of 335 eligible patients (64\% male; mean age 68 years) were reviewed, including all 137 with bacteriuria, and 198 with negative urine cultures. In total, $51 \%$ of the urine specimens were obtained from an indwelling urinary catheter, and 28\% were voided urine samples. Confusion (57\%) and fever (36\%) were the most common indications noted for obtaining the urine cultures. Only 34 patients ( $25 \%$ of those with positive urine cultures) met the criteria for a symptomatic urinary tract infection; 67 (49\%) had asymptomatic bacteriuria and 36 (26\%) had infection at a nonurinary site. Of those with asymptomatic bacteriuria, $64 \%$ received antimicrobial therapy for a total of 347 days. Confused patients with asymptomatic bacteriuria were more likely to be treated than were bacteriuric patients without altered mental status (OR $1.8,95 \%$ CI 1.2 to $4.1 ; \mathrm{P}=0.03$ ).

CONCLUSIONS: Urine cultures are frequently obtained from hospitalized patients, even in the absence of urinary symptoms. Asymptomatic bacteriuria is often treated in these patients, and accounts for a substantial burden of inappropriate antimicrobial use in hospitals. Effective strategies to improve urine culture ordering and antimicrobial utilization in hospitals need to be implemented.

Key Words: Antimicrobial treatment; Asymptomatic bacteriuria; Laboratory utilization; Urinary tract infection

\section{Les uricultures positives : Une cause majeure d'utilisation inopportune d'antimicrobiens en milieu hospitalier?}

INTRODUCTION : Les échantillons d'urine font partie des prélèvements les plus mis en culture aux laboratoires de microbiologie. La présente étude vise à décrire les indications pour obtenir des uricultures au sein d'une cohorte de patients hospitalisés et à déterminer la pertinence d'un traitement antimicrobien en réponse aux résultats de l'uriculture.

MÉTHODOLOGIE : L'étude a eu lieu entre le $1^{\text {er }}$ juin et le 31 juillet 2006 à un hôpital universitaire doté d'un établissement connexe de soins de longue durée. Les auteurs ont examiné les dossiers médicaux de patients adultes non enceintes avec ou sans bactériurie. L'infection urinaire symptomatique était définie comme la présence de bactériurie chez un patient faisant de la fièvre ou ayant des symptômes urinaires. La bactériurie asymptomatique était plutôt définie comme une bactériurie sans symptômes urinaires et sans infection évidente à un autre foyer.

RÉSULTATS : Les auteurs ont examiné le dossier médical de 355 patients admissibles (64\% de sexe masculin, âge moyen de 68 ans), y compris les 137 ayant une bactériurie, et celui de 198 patients dont l'uriculture était négative. Au total, $51 \%$ des échantillons d'urine avaient été prélevés dans un cathéter à demeure, et $28 \%$ par réflexe mictionnel. La confusion (57 \%) et la fièvre (36 \%) étaient les principales indications consignées pour justifier une uriculture. Seulement 34 patients ( $25 \%$ de ceux dont l'uriculture était positive) respectaient les critères d'infection urinaire symptomatique, 67 (49\%) avaient une bactériurie asymptomatique et 36 ( $26 \%)$, une infection à un foyer non urinaire. Parmi les patients atteints de bactériurie asymptomatique, $64 \%$ ont reçu un traitement antimicrobien pendant un total de 347 jours. Les patients confus ayant une bactériurie asymptomatique étaient plus susceptibles d'être traités que les patients bactériuriques dont l'état mental n'était pas altéré (RRR 1,8; 95 \% IC 1,2 à 4,$1 ; \mathrm{P}=0,03)$.

CONCLUSION : On prélève souvent des uricultures auprès des patients hospitalisés, même en l'absence de symptômes urinaires. On traite souvent la bactériurie asymptomatique chez ces patients, ce qui représente un fardeau important d'utilisation inopportune d'antimicrobiens en milieu hospitalier. Des stratégies efficaces s'imposent pour améliorer les commandes d'uriculture et l'utilisation d'antimicrobiens en milieu hospitalier.
$\mathrm{T}_{\mathrm{fi}}^{\mathrm{h}}$ he diagnosis of a urinary tract infection (UTI) is confirmed by obtaining a urine culture that yields a significant quantity of microbial growth. Urine specimens are generally easy to obtain from adult patients, and represent one of the most common clinical samples submitted to hospital microbiology laboratories (1). A urine culture result indicating the presence of bacterial growth often triggers a prescription for an antimicrobial agent $(2,3)$. However, the diagnosis of UTI in hospitalized patients is not always straightforward, and antimicrobial therapy may not be appropriate just because there is bacteriuria. Challenges faced by clinicians in determining the significance of a urine culture result include the presence of nonspecific or atypical clinical presentations in bacteriuric patients, or the inability of a hospitalized patient to express or describe urinary symptoms (1). Asymptomatic bacteriuria, generally defined as bacteriuria in the absence of urinary symptoms, is relatively common in adults, but in most cases should not be treated, although the management of asymptomatic bacteriuria in hospitalized patients has not been addressed in published guidelines $(4,5)$. In the present study, we wished to determine the circumstances under which adult patients admitted to our hospital 
had urine cultures obtained, and to describe the pattern of antimicrobial use in response to urine culture results.

\section{METHODS}

The study was conducted at Sunnybrook Health Sciences Centre, Toronto, Ontario, a 1100-bed university-affiliated teaching hospital with 120 intensive care unit (ICU) beds and 535 long-term care beds. Each day from June 1 to July 31, 2006, all inpatients with a 'positive' urine culture result were identified. For each patient with a positive urine culture, an attempt was made to also identify two eligible patients with 'negative' urine cultures obtained within $12 \mathrm{~h}$ on the same day. All nonpregnant adult (older than 18 years of age) inpatients were included in the study unless they were hospitalized on the nephrology, urology or oncology service, or if the urine samples were obtained during a cystoscopy, or from nephrostomy or ileostomy drainage. Duplicate urine samples were excluded so that each patient was enrolled only once (with their first culture). The medical and microbiology laboratory records of each enrolled patient were reviewed within seven days after the urine culture results were available, using a standard data collection tool for demographic and clinical data regarding the circumstances surrounding the selected urine cultures, patient diagnosis and antimicrobial therapy. Outcome (in-hospital mortality) was determined at four weeks after the initial culture date.

Urine cultures were ordered at the discretion of the attending physician or nurse practitioner, and were processed by the hospital's microbiology laboratory using standard quantitative culture methods $(1,6)$. Urine specimens were kept refrigerated at $4^{\circ} \mathrm{C}$ until processing, generally within $2 \mathrm{~h}$ of receipt in the laboratory. Specimens that were received $24 \mathrm{~h}$ or more after procurement were rejected and not cultured.

Positive urine cultures were defined as those with significant microbial growth determined by standard microbiological criteria $(1,6)$. Negative urine cultures included those with no growth, with an insignificant quantity of growth or those with mixed growth due to probable contaminants. A symptomatic UTI was determined to be present if there was a positive urine culture from a patient with fever (greater than $38^{\circ} \mathrm{C}$ ) without another explanation, or from a patient who had at least one urinary symptom (dysuria, urgency, frequency, or suprapubic pain or tenderness) $(7,8)$. A nosocomial UTI was defined by a urine culture obtained after $48 \mathrm{~h}$ of admission to hospital. A patient with a positive urine culture was assumed to have asymptomatic bacteriuria if there were no signs or symptoms referable to the urinary tract, no fever, and no evidence of infection at another site $(4,7,9)$. Other sites of infection were defined by standard criteria used for nosocomial infections (8). The appropriateness of antimicrobial therapy for patients with asymptomatic bacteriuria was determined in accordance with published guidelines (4).

Statistical analyses were done by Student's $t$ test, the $\chi^{2}$ test and Fisher's exact test, as appropriate. All statistical tests were two-tailed, with a $\mathrm{P} \leq 0.05$ considered statistically significant.

The study was approved by the Research Ethics Board of the Sunnybrook Health Sciences Centre.

\section{RESULTS}

During the study, a total of 2002 urine specimens obtained from 888 inpatients were submitted to the microbiology laboratory for culture. These specimens were obtained from ICU patients (135 cultures per 1000 patient-days), patients admitted to medical services ( 54 cultures per 1000 patientdays) and surgical services (47 cultures per 1000 patient-days), and from those residing on long-term care units (54 cultures per 1000 patient-days). Urine specimens were the third most common type of specimen submitted to the microbiology laboratory (after screening specimens for antibiotic-resistant organisms and blood cultures), representing $12 \%$ of all specimen types submitted for culture.

There were 399 (20\%) urine cultures that met microbiologic criteria for significant growth of organisms, and were considered to be positive urine cultures. Medical records of 335 eligible patients were available for review, and included all 137 patients with positive urine cultures and 198 patients with negative cultures. The mean age $( \pm S D)$ of these patients was $68.1 \pm 9.4$ years. There were $214(64 \%)$ male patients, but women were more likely to have had a positive urine culture (63 [52\%] women compared with 75 [35\%] men; OR 1.85, 95\% CI 1.18 to $5.07 ; \mathrm{P}=0.03$ ). Most patients (82\%) had at least one underlying comorbidity, most commonly coronary artery disease $(40 \%)$, diabetes mellitus (25\%), malignancy $(23 \%)$, dementia $(17 \%)$, cerebrovascular accident $(16 \%)$ and chronic obstructive pulmonary disease (12\%). There was no significant difference in the prevalence of positive urine cultures obtained from patients in the ICU (38\%), medical (40\%) or surgical $(38 \%)$ wards, or long-term care $(49 \%)$ patients.

Urine specimens were obtained from an indwelling (Foley) urinary catheter in 170 patients (51\%), from an in/out urinary catheter in 30 patients (9\%), and from condom catheter drainage in nine patients (3\%). A voided urine sample was obtained from 95 patients (28\%), and for 31 cases $(9 \%)$ the source of the urine specimen was not specified. Excluding long-term care patients, urine cultures were obtained a mean of 9.3 days after hospital admission. Specimens yielding a positive urine culture were obtained a mean of 14.8 days after admission versus a mean of 6.3 days after admission for specimens that were considered to have negative urine cultures $(\mathrm{P}=0.04)$.

Almost all (90\%) of the urine cultures had been ordered by a physician (a physician's order was evident in the medical records), and a presumed indication for obtaining the urine cultures (based on written documentation in the chart) was noted for 320 cases (96\%). The most common indications noted were confusion or altered mental status in 191 patients $(57 \%)$, and fever in 122 patients (36\%) (Table 1). Those with negative urine cultures were more likely to have been febrile (43\%) than were those with positive urine cultures (27\%) (OR $7.40,95 \%$ CI 2.08 to $26.28 ; \mathrm{P}<0.001$ ), possibly because patients with negative urine cultures were more likely to have had an infection at a nonurinary site (48\%), compared with those with positive urine cultures (26\%) (Table 2). Urinary symptoms were noted to be present in 75 patients (22\%), and those with any urinary symptom were more likely to have had a positive urine culture (OR 1.58, 95\% CI 0.99 to 2.52; $\mathrm{P}=0.06$ ). Cloudy or malodorous urine was a reported indication for obtaining a urine culture in 19 patients (6\%).

Of the 137 patients with a positive urine culture, 67 (49\%) had asymptomatic bacteriuria, and 36 (26\%) had evidence of infection at a nonurinary site (Table 2). Only 34 patients (25\%) met criteria for a symptomatic UTI, and most (71\%) 
TABLE 1

Symptoms of patients with positive or negative urine cultures on the day urine specimens were obtained for culture

\begin{tabular}{lcccc}
\hline & $\begin{array}{c}\text { Total study } \\
\text { population } \\
(\mathbf{n = 3 3 5 )}\end{array}$ & $\begin{array}{c}\text { Negative } \\
\text { cultures } \\
(\mathbf{n}=198)\end{array}$ & $\begin{array}{c}\text { Positive } \\
\text { cultures } \\
(\mathbf{n}=137)\end{array}$ & $\mathbf{P}$ \\
\hline Symptom, $\mathbf{n}(\%)$ & $122(36)$ & $85(43)$ & $37(27)$ & $<0.001$ \\
Confusion or altered & $191(57)$ & $114(58)$ & $77(56)$ & 0.82 \\
$\quad$ mental status & $26(8)$ & $12(6)$ & $14(10)$ & 0.21 \\
Dysuria & $12(4)$ & $8(4)$ & $4(3)$ & 0.77 \\
Urgency & $21(6)$ & $10(5)$ & $11(8)$ & 0.36 \\
Frequency & $9(3)$ & $4(2)$ & $5(4)$ & 0.50 \\
Suprapubic pain or & $19(6)$ & $9(5)$ & $10(7)$ & 0.34 \\
$\quad$ tenderness & $18(5)$ & $11(6)$ & $7(5)$ & 0.98 \\
New incontinence & $34(10)$ & $20(10)$ & $14(10)$ & 0.99 \\
Gross hematuria & $47(14)$ & $29(15)$ & $18(13)$ & 0.75 \\
Back or flank pain & $17(5)$ & $3(2)$ & $14(10)$ & $<0.001$ \\
Nausea or vomiting & $7(2)$ & 0 & $7(5)$ & 0.58 \\
Cloudy urine & $15(5)$ & $11(6)$ & $4(3)$ & 0.29 \\
Malodorous urine & & &
\end{tabular}

were nosocomial. Compared with a voided urine, a catheter urine specimen was more likely to yield a positive culture (OR $2.12,95 \%$ CI 1.24 to $3.62 ; \mathrm{P}=0.006$ ), but it was not more likely to be associated with a symptomatic UTI (OR 1.19, 95\% CI 0.49 to $2.86 ; \mathrm{P}=0.83)$. Most patients $(63 \%)$ with asymptomatic bacteriuria had confusion, delirium or a decreased level of consciousness, but more than one-half of patients (56\%) with a symptomatic UTI also presented with confusion or an altered level of consciousness in addition to one or more urinary symptom. There were no significant differences in the rates of UTI or asymptomatic bacteriuria among patients admitted to various hospital services (Table 3).

The organisms isolated in urine cultures of patients with UTI and asymptomatic bacteriuria are summarized in Table 3. There were no vancomycin-resistant enterococci. Although only two isolates (one Escherichia coli and one Klebsiella pneumoniae) were determined to produce an extended-spectrum beta-lactamase, $39 \%$ of the $E$ coli isolates were resistant to trimethoprim-sulfamethoxazole and $31 \%$ were fluoroquinolone resistant; $33 \%$ of the Pseudomonas aeruginosa isolates were resistant to fluoroquinolones. Blood cultures were obtained within $24 \mathrm{~h}$ of the urine culture from 164 patients (49\%). Twenty-seven (8\%) patients were bacteremic, and most $(81 \%)$ of these patients had negative urine cultures. Only three patients (all with symptomatic UTI) had the same organism in a blood culture as in their urine culture (two with E coli, and one with Serratia marcescens).

Ninety-seven $(71 \%)$ of those with a positive urine culture were treated with an antimicrobial agent for a presumed or possible UTI, including $30(88 \%)$ of the 34 patients with symptomatic UTI and $43(64 \%)$ of those with asymptomatic bacteriuria. Rates of antimicrobial therapy for asymptomatic bacteriuria ranged from $47 \%$ of surgical patients to $71 \%$ of ICU patients $(\mathrm{P}=0.15)$. Confused patients with asymptomatic bacteriuria were more likely to be treated than were bacteriuric patients without confusion or altered mental status $(75 \%$ versus 43\%; OR 1.81, 95\% CI 1.19 to $4.12 ; \mathrm{P}=0.03)$. The
TABLE 2

Clinical syndromes associated with urine culture results

\begin{tabular}{lccc}
\hline Clinical syndrome & $\begin{array}{c}\text { Total enrolled, Positive urine } \\
\mathbf{n}(\%)\end{array}$ & $\begin{array}{c}\text { Negative urine } \\
\text { culture, } \mathbf{n}(\%)\end{array}$ & culture, $\mathbf{n}(\%)$ \\
\hline $\begin{array}{l}\text { Symptomatic urinary tract } \\
\text { infection }\end{array}$ & $34(10)$ & $34(25)$ & 0 \\
$\begin{array}{l}\text { Asymptomatic bacteriuria } \\
\text { Infection at another } \\
\text { (nonurinary) site }\end{array}$ & $67(20)$ & $67(49)$ & 0 \\
$\begin{array}{l}\text { No infection and no } \\
\text { bacteriuria }\end{array}$ & $130(39)$ & $36(26)$ & $94(48)$ \\
\hline
\end{tabular}

TABLE 3

Selected characteristics and urinary isolates from patients with symptomatic urinary tract infections and asymptomatic bacteriuria

\begin{tabular}{|c|c|c|c|}
\hline Characteristic & $\begin{array}{c}\text { Asympomatic } \\
\text { bacteriuria } \\
(n=67)\end{array}$ & $\begin{array}{c}\text { Symptomatic } \\
\text { urinary tract } \\
\text { infection }(n=34)\end{array}$ & $\mathbf{P}$ \\
\hline Mean age (years) & 75.8 & 72.6 & 0.56 \\
\hline Male sex & $30(45)$ & $20(59)$ & 0.07 \\
\hline Intensive care unit patient & $14(21)$ & $6(18)$ & 0.80 \\
\hline Medical patient & $16(24)$ & $9(26)$ & 0.81 \\
\hline Surgical patient & $15(22)$ & $7(21)$ & 0.99 \\
\hline Long-term care patient & $22(33)$ & $12(35)$ & 0.83 \\
\hline $\begin{array}{l}\text { Presented with confusion or } \\
\text { altered level of consciousness }\end{array}$ & $44(66)$ & $19(56)$ & 0.17 \\
\hline \multicolumn{4}{|l|}{ Urinary specimen } \\
\hline Voided urine & $12(18)$ & $10(29)$ & 0.21 \\
\hline In/out catheter & $9(13)$ & $4(12)$ & 1.00 \\
\hline Indwelling catheter & $37(55)$ & $14(41)$ & 0.22 \\
\hline Condom drainage & $5(7)$ & $0(0)$ & 0.33 \\
\hline Not known & $4(6)$ & $6(18)$ & 0.21 \\
\hline \multicolumn{4}{|l|}{ Urine isolate } \\
\hline Escherichia coli & $26(39)$ & $16(47)$ & 0.52 \\
\hline Klebsiella pneumoniae & $11(16)$ & $1(3)$ & 0.06 \\
\hline Proteus species & $5(7)$ & $3(9)$ & 0.67 \\
\hline Enterobacter species & $4(6)$ & $2(6)$ & 1.00 \\
\hline Enterococcus species & $15(22)$ & $8(24)$ & 0.99 \\
\hline Candida species & $3(5)$ & $2(6)$ & 0.99 \\
\hline Other organisms & $11(16)$ & $4(12)$ & 0.61 \\
\hline
\end{tabular}

most commonly used antimicrobial agents for treatment of a symptomatic infection and for asymptomatic bacteriuria were beta-lactams (48\%) and fluoroquinolones (42\%). The mean duration of antimicrobial therapy was 8.8 days for symptomatic UTI and 8.1 days in patients with asymptomatic bacteriuria $(\mathrm{P}=0.31)$. There was no difference in in-hospital mortality rates for those with a symptomatic UTI $(2.9 \%)$ compared with those with asymptomatic bacteriuria $(1.5 \%)(\mathrm{P}=0.89)$, nor was there a difference in mortality for those with asymptomatic bacteriuria who received antimicrobial therapy (0) compared with those who were not treated $(4.2 \%)(\mathrm{P}=0.36)$.

\section{DISCUSSION}

UTIs are the most common cause of nosocomial infections in North America, accounting for 35\% to $40 \%$ of all hospitalacquired infections $(10,11)$. Hospitalized patients may be at increased risk of developing a UTI because of advanced age, 
due to the presence of underlying diseases such as diabetes mellitus or stroke, or because of urinary tract obstruction $(12,13)$. Most UTIs in hospitalized patients occur in the presence of a urinary catheter $(14,15)$. The diagnosis of a UTI is often signalled by the presence of fever, or irritative urinary symptoms (dysuria, urgency, frequency), and is confirmed with a urine culture that yields significant microbial growth. However, catheter-associated bacteriuria is usually asymptomatic (16). Importantly though, catheter-associated bacteriuria comprises a significant reservoir of antibiotic-resistant organisms that may be transmitted in the hospital environment (17-19).

Evidence-based guidelines have emphasized that screening for or treatment of asymptomatic bacteriuria in many patient populations is not recommended $(4,20)$. Numerous studies have documented that treatment of asymptomatic bacteriuria in these patient populations provides no benefit, and may be associated with increased risk of adverse reactions or reinfection with organisms of increasing antimicrobial resistance $(9,12,21-25)$. However, the guidelines for not treating asymptomatic bacteriuria do not specifically address management of hospitalized bacteriuric patients who are acutely ill with confusion or an altered mental status but without symptoms referable to the urinary tract. Data are also lacking with regard to the appropriate management of asymptomatic bacteriuria in patients who are neutropenic or immunocompromised, who have chronic renal disease or who have undergone renal transplantation.

In the present study, only a minority (25\%) of those with bacteriuria met standard criteria for a symptomatic UTI, and approximately the same number of patients had evidence of infection at a nonurinary site. Therefore, approximately onehalf of the bacteriuric patients were considered to have had asymptomatic bacteriuria. Urine cultures were often obtained from patients presenting with confusion or fever, without urinary symptoms. As has been described previously in elderly subjects $(26,27)$, these nonspecific symptoms were not predictive of bacteriuria or of a symptomatic UTI. The presence of cloudy or malodorous urine was also, inappropriately (28), an indication for obtaining a urine culture in some patients. There is now a substantial body of evidence, in many different patient populations, to support published recommendations that patients without fever or urinary symptoms should not have urine cultures done despite the presence of other nonspecific, nonurinary symptoms; moreover, if urine cultures are done, it is clear that there is no benefit of antimicrobial therapy for those found to have asymptomatic bacteriuria $(9,12,21-24)$.

In the present study, most (64\%) patients with asymptomatic bacteriuria, whether it was catheter-associated or not, received antimicrobial therapy. This represented 43 patients who received a total of 347 days of inappropriate antimicrobial therapy according to published guidelines (4), within a two month period of time. This is likely an underestimate because patients with fever and bacteriuria were considered to have had a symptomatic UTI, even though the fever may have been unrelated to the positive urine culture. Urine cultures were obtained more often, and asymptomatic bacteriuria was more likely to have been treated in ICU patients, and in those who presented with confusion. Presumably, these patients were thought to have been septic, possibly from a urinary source.
However, even if the presence of acute confusion or delirium as possible manifestations of sepsis warrants empirical antimicrobial therapy, that would still have left $43 \%$ of hospitalized patients with asymptomatic bacteriuria who were treated inappropriately with antibiotics.

Asymptomatic bacteriuria has frequently been recognized as an important reason for inappropriate use of antibiotics in elderly long-term care facility residents $(2,29,30)$. However, the frequency of treatment of asymptomatic bacteriuria as a cause of inappropriate antimicrobial utilization in hospital settings has not been well documented. In one hospital-based study, asymptomatic bacteriuria or funguria was a relatively common clinical scenario associated with unnecessary antibiotic use, accounting for 99 days of inappropriate treatment during two weeks of surveillance (3). Our study adds to existing evidence that the presence of bacteriuria in hospitalized patients often leads to inappropriate antibiotic treatment, and that this represents an important opportunity to improve the quality of patient care. Strategies to ensure appropriate ordering of urine cultures and an appropriate response to those that are positive need to be developed and evaluated. For example, in a randomized controlled trial a multifaceted diagnostic and treatment algorithm that incorporated evidence-based guidelines for obtaining urine cultures and starting antimicrobial therapy was found to be effective in reducing inappropriate antibiotic use in nursing home residents with bacteriuria (31). Perhaps a similar approach would also be effective in hospitals. The implementation of an antimicrobial stewardship program may also assist in optimizing antibiotic utilization in hospitals (32).

The present study was done in a teaching hospital and the results may not be generalizeable to other health care settings. Certain patient populations were excluded because of lack of clarity of treatment guidelines for these patients (eg, febrile neutropenic patients with asymptomatic bacteriuria). Patients with negative urine cultures included in the present study were a convenience sample, and may not have been representative of all patients without bacteriuria. Other study limitations included the lack of outcome data other than in-hospital allcause mortality in patients who received or did not receive antimicrobial therapy.

\section{CONCLUSIONS}

We have determined that the presence of nonurinary symptoms and signs are an important factor in ordering urine cultures and influencing the decision to prescribe antimicrobial agents in hospitalized patients, similar to findings that have been reported in long-term care facilities for the elderly (2). Treatment of asymptomatic bacteriuria appears to be an important cause of inappropriate antibiotic use in hospitals, and may therefore contribute to the emergence of antimicrobial resistance. We agree with the recent proposal that hospital quality performance measures should be created for not treating asymptomatic bacteriuria in adults (5). Greater attention should also be devoted to implementing proven measures to reduce the incidence of nosocomial and catheter-related UTIs (33). Future studies should address the management of bacteriuria in hospitalized patients with an acute change in mental status, with febrile neutropenia, and in renal transplant recipients. 


\section{REFERENCES}

1. Wilson ML, Gaido L. Laboratory diagnosis of urinary tract infections in adult patients. Clin Infect Dis 2004;38:1150-8.

2. Walker S, McGeer A, Simor AE, Armstrong-Evans M, Loeb M. Why are antibiotics prescribed for asymptomatic bacteriuria in institutionalized elderly people? A qualitative study of physicians' and nurses' perceptions. Can Med Assoc J 2000;163:273-7.

3. Hecker MT, Aron DC, Patel NP, Lehmann MK, Donskey CJ. Unnecessary use of antimicrobials in hospitalized patients. Current patterns of misuse with an emphasis on the antianaerobic spectrum of activity. Arch Intern Med 2003;163:972-8.

4. Nicolle LE, Bradley S, Colgan R, Rice JC, Schaeffer A, Hooton TM. Infectious Diseases Society of America Guidelines for the diagnosis and treatment of asymptomatic bacteriuria in adults. Clin Infect Dis 2005;40:643-54.

5. Gross PA, Patel B. Reducing antibiotic overuse: a call for a national performance measure for not treating asymptomatic bacteriuria. Clin Infect Dis 2007;45:1335-7.

6. Clarridge JE, Johnson JR, Pezzlo MT. Cumitech 2B, Laboratory diagnosis of urinary tract infections. American Society for Microbiology, Washington, DC, 1998.

7. Rubin RH, Shapiro ED, Andriole VT, Davis RJ, Stamm WE. Evaluation of new anti-infective drugs for the treatment of urinary tract infection. Clin Infect Dis 1992;15 (Suppl. 1):S216-27.

8. Horan TC, Andrus M, Dudeck MA. CDC/NHSN surveillance definition of health care-associated infection and criteria for specific types of infections in the acute care setting. Am J Infect Control 2008;36:309-32.

9. Harding GKM, Zhanel GG, Nicolle LE, Cheang M, Manitoba Diabetes Urinary Tract Infection Study Group. Antimicrobial treatment of diabetic women with asymptomatic bacteriuria. $\mathrm{N}$ Engl J Med 2002;347:1576-83.

10. NNIS System, Division of Healthcare Quality Promotion, National Center for Infectious Diseases, Centers for Disease Control and Prevention. National Nosocomial Infections Surveillance (NNIS) System Report, data summary from January 2002 through June 2004, issued October 2004. Am J Infect Control 2004;32:470-85.

11. Klevens RM, Edwards JR, Richards Jr CL, et al. Estimating health care-associated infections and deaths in U.S. hospitals, 2002. Public Health Reports 2007;122:160-6.

12. Nicolle LE, Bjornson J, Harding GKM, MacDonell JA. Bacteriuria in elderly institutionalized men. N Engl J Med 1983;309:1420-5.

13. Zhanel GG, Nicolle LE, Harding GKM, Manitoba Diabetic Urinary Infection Study Group. Prevalence of asymptomatic bacteriuria and associated host factors in women with diabetes mellitus. Clin Infect Dis 1995;21:316-22.

14. Stamm WE. Catheter-associated urinary tract infections: epidemiology, pathogenesis, and prevention. Am J Med 1991;91(Suppl 3B):65S-71S.

15. Tambyah PA, Knasinski V, Maki DG. The direct costs of nosocomial catheter-associated urinary tract infection in the era of managed care. Infect Control Hosp Epidemiol 2002;23:27-31.

16. Tambyah PA, Maki DG. Catheter-associated urinary tract infection is rarely symptomatic. A prospective study of 1497 catheterized patients. Arch Intern Med 2000;160:678-82.
17. Schaberg DR, Haley RW, Highsmith AK, Anderson RL, McGowan JE Jr. Nosocomial bacteriuria: a prospective study of case clustering and antimicrobial resistance. Ann Intern Med 1980;93:420-4.

18. Gaynes RP, Weinstein RA, Chamberlin W, Kabins S. Antibioticresistant flora in nursing home patients admitted to hospital. Arch Intern Med 1985;145:1804-7.

19. Jarlier V, Fosse T, Philippon A. Antibiotic susceptibility in aerobic gram-negative bacilli isolated in intensive care units in 39 French teaching hospitals. Intensive Care Med 1996;22:1057-65.

20. U.S. Preventive Services Task Force. Screening for asymptomatic bacteriuria in adults: U.S. Preventive Services Task Force reaffirmation recommendation statement. Ann Intern Med 2008;149:43-7.

21. Warren JW, Anthony WC, Hoopes JM, Muncie HL Jr. Cephalexin for susceptible bacteriuria in afebrile, long-term care catheterized patients. JAMA 1982;248:454-8.

22. Nicolle LE, Mayhew WJ, Bryan L. Prospective randomized comparison of therapy and no therapy for asymptomatic bacteriuria in institutionalized elderly women. Am J Med 1987;83:27-33.

23. Boscia JA, Kobasa WD, Knight RA, Abrutyn E, Levison ME, Kaye D. Therapy vs no therapy for bacteriuria in elderly, ambulatory, nonhospitalized women. JAMA 1987;257:1061-71.

24. Cardenas DD, Hooton TM. Urinary tract infection in persons with spinal cord injury. Arch Phys Med Rehabil 1995;76:272-80.

25. Leone M, Perrin A-S, Granier I, et al. A randomized trial of catheter change and short course of antibiotics for asymptomatic bacteriuria in catheterized ICU patients. Intensive Care Med 2007;33:726-9.

26. Boscia JA, Kobasa WD, Abrutyn E, Levison ME, Kaplan AM, Kaye D. Lack of association between bacteriuria and symptoms in the elderly. Am J Med 1986;81:979-82.

27. Orr PH, Nicolle LE, Duckworth H, et al. Febrile urinary infection in the institutionalized elderly. Am J Med 1996;100:71-7.

28. Nicolle LE, SHEA Long-Term-Care Committee. Urinary tract infections in long-term-care facilities. SHEA Position Paper. Infect Control Hosp Epidemiol 2001;22:167-75.

29. Warren JW, Palumbo FB, Fitterman L, Speedie SM. Incidence and characteristics of antibiotic use in aged nursing home patients. J Am Geriatr Soc 1991;39:963-72.

30. Nicolle LE, Bentley DW, Garibaldi R, Neuhaus EG, Smith PW, SHEA Long-Term-Care Committee. Antimicrobial use in longterm-care facilities. Infect Control Hosp Epidemiol 2000;21:537-45.

31. Loeb M, Brazil K, Lohfeld L, et al. Effect of a multifaceted intervention on number of antimicrobial prescriptions for suspected urinary tract infections in residents of nursing homes: cluster randomised controlled trial. Brit Med J 2005; epub doi:10.1136/ bmj.38602.586343.55 (published 8 September 2005).

32. Dellit TH, Owens RC, McGowan JE Jr, et al. Infectious Diseases Society of America and the Society for Healthcare Epidemiology of America Guidelines for developing an institutional program to enhance antimicrobial stewardship. Clin Infect Dis 2007;44:159-77.

33. Saint S, Kowalski CP, Kaufman SR, et al. Preventing hospitalacquired urinary tract infection in the United States: a national survey. Clin Infect Dis 2008;46:243-50. 


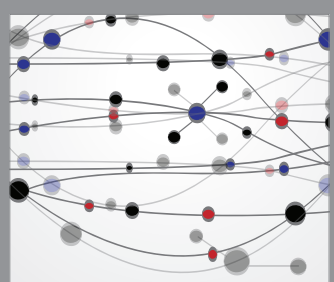

The Scientific World Journal
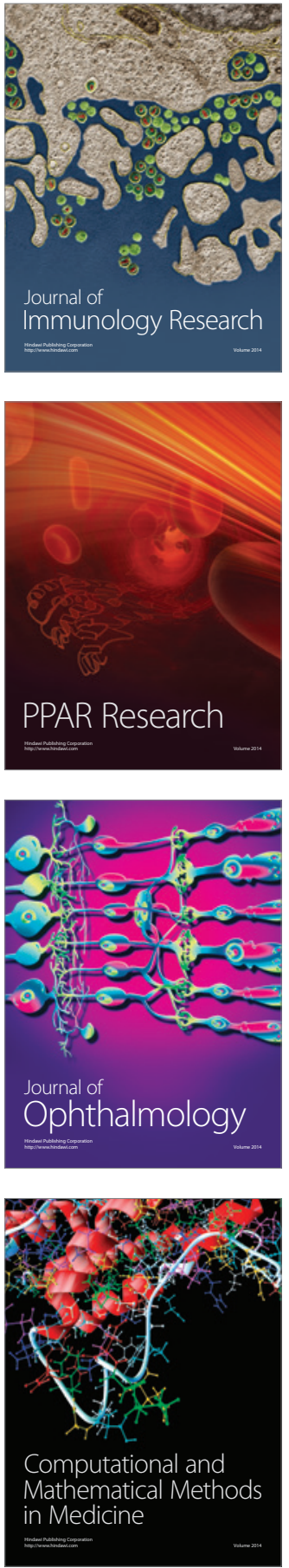

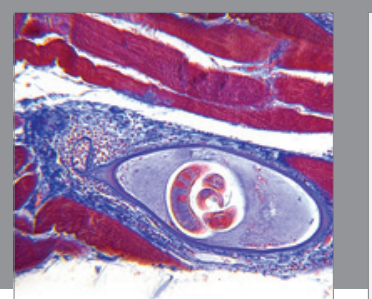

Gastroenterology Research and Practice

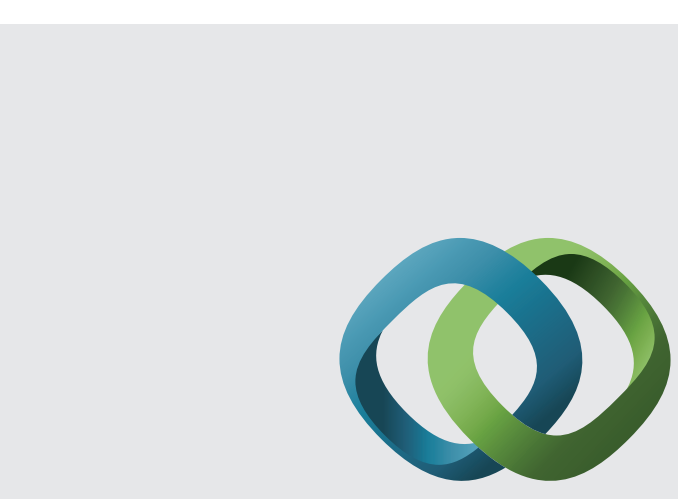

\section{Hindawi}

Submit your manuscripts at

http://www.hindawi.com
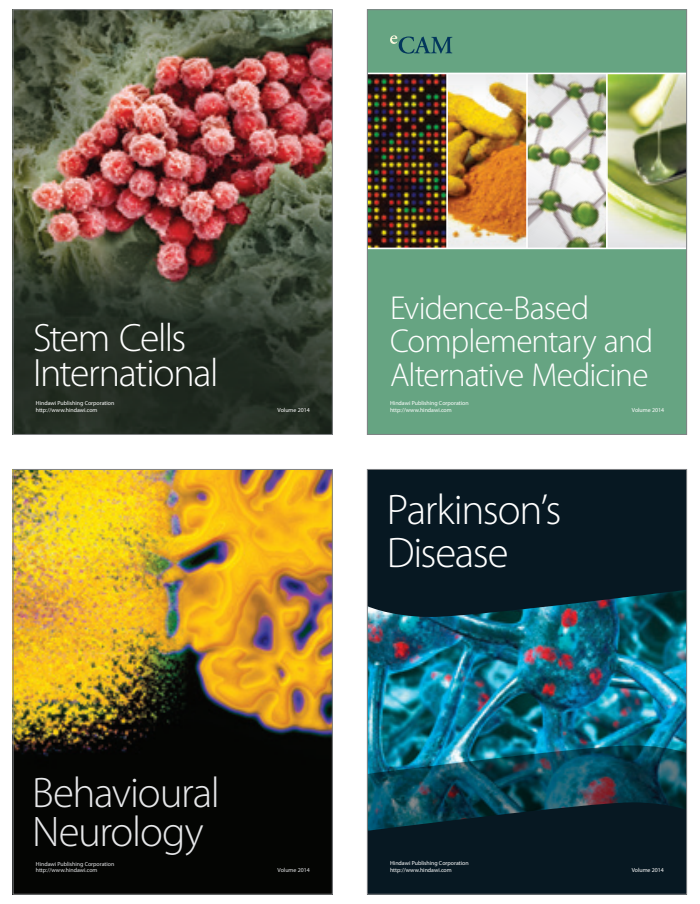
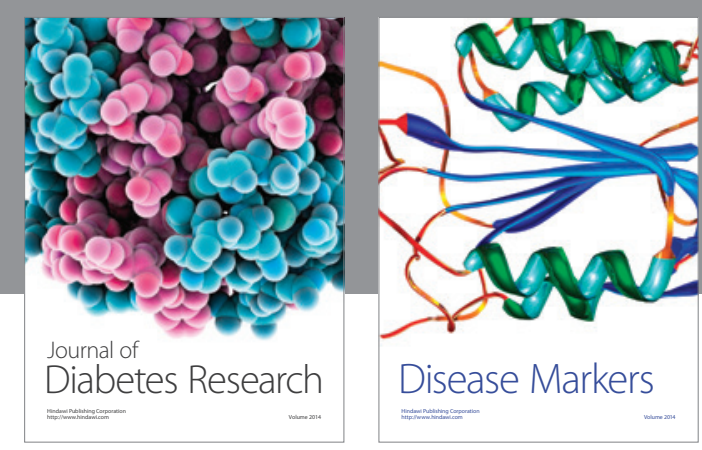

Disease Markers
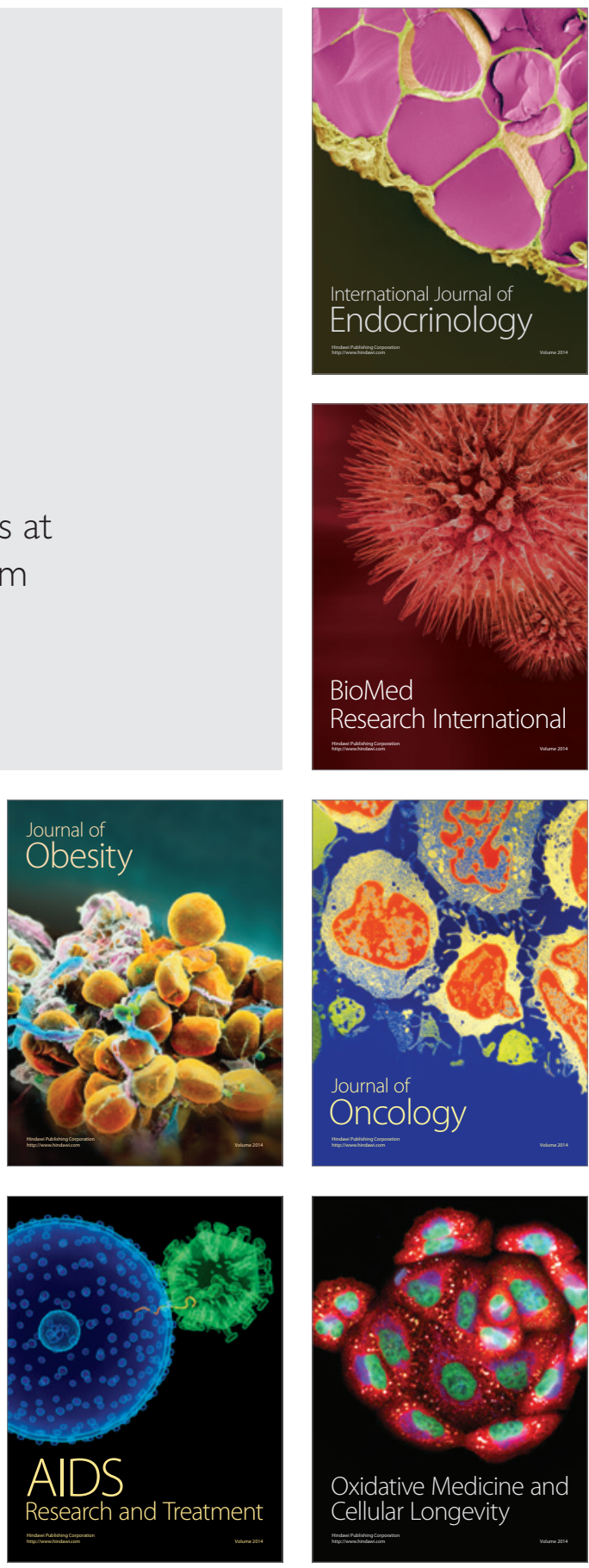